\title{
RIFAXIMIN INDUCED HYPONATREMIA: A CASE REPORT
}

\author{
PRABHAT AGRAWAL ${ }^{1}$, MANISH BANSAL ${ }^{1}$, SHALINI UPADHYAY ${ }^{1 *}$, ANJALIKA GUPTA ${ }^{2}$
}

1'Department of Medicine, SNMC, Agra, India. ²Department of Medicine, BM Gupta Hospital, Delhi, India. Email:ushalini19@yahoo.com Received: 02 August 2016, Revised and Accepted: 10 September 2016

\section{ABSTRACT}

Rifaximin is one of the common drugs used in clinical practice in the management of traveler's diarrhea, irritable bowel syndrome (IBS), and hepatic encephalopathy. Hyponatremia is one of the rare side effects of this drug. We hereby present the case of a middle-aged woman who was a known case of IBS: Diarrhea predominant who developed symptoms of hyponatremia after a short duration of rifaximin treatment, no other cause of hyponatremia was found on evaluation, so we suspect this as a rare side effect of rifaximin therapy.

Keywords: Rifaximin, Hyponatremia, Irritable bowel syndrome.

(C) 2016 The Authors. Published by Innovare Academic Sciences Pvt Ltd. This is an open access article under the CC BY license (http://creativecommons. org/licenses/by/4. 0/) DOI: http://dx.doi.org/10.22159/ajpcr.2016.v9s3.14452

\section{INTRODUCTION}

Rifaximin is a semi synthetic antibiotic which is used in the treatment of traveler's diarrhea [1], IBS [2], and hepatic encephalopathy [3]. Some common side effects of this drug are nausea, vomiting, rectal tenesmus, abdominal pain, defecation urgency, nausea, and constipation. One of the rare metabolic side effects of this drug is hyponatremia which can manifest as malaise, lethargy, decreased level of consciousness, headache, and seizures and coma.

\section{CASE REPORT}

A 35-year-old female was brought to emergency department with drowsiness for 2 days; on enquiry it was found that she is a known case of irritable bowel syndrome (IBS): Diarrhea predominant from 6 to 7 years.

Recently, she was advised tablet Rifaximin $550 \mathrm{mg}$ BD by a private practitioner and she was taking it for last 5-6 days. However, for past 2 days, her family members noticed she was unusually drowsy and she has been brought to our department for the same complaints, on further evaluation her vitals were stable. On general examination, there was mild pallor and rest were normal, cardiovascular system, gastrointestinal tract, and respiratory system were normal, pt was drowsy but oriented to time, place and person, planter was bilateral flexor, meningeal signs were absent, reflex, power was normal. $24 \mathrm{hrs}$ output was approximately $2 \mathrm{l}$. On laboratory examination routine blood investigations complete blood count (Hb-8.2, TLC-6200, differential leukocyte count-neutrophils $82 \%$, lymphocyte $18 \%$, platelets 2,20,000, ESR-44), liver function test (serum glutamic oxaloacetic transaminase-22, serum glutamic-pyruvic transaminase-44), and kidney function test (serum creatnine-0.9, blood urea-34 mg/dl) were unremarkable except serum electrolytes (serum $\mathrm{Na}+=118 \mathrm{meq} / \mathrm{l}$; $\mathrm{S} . \mathrm{K}+=4.5$; serum $\mathrm{Ca}++=1.02$ ). Plasma osmolarity came out to be $255 \mathrm{mOsm} / \mathrm{L}$, urine osmolarity was $112 \mathrm{mOsm} / \mathrm{L}$ and urinary $(\mathrm{Na}+)$ was $8 \mathrm{mEq} / \mathrm{L}$. Viral markers (HIV/HbsAg/Anti-HCV) were negative. Computerized tomography scan brain was normal. She was managed conservatively with hypertonic saline $(3 \% \mathrm{NaCl})$ and patient improved on the $2^{\text {nd }}$ day of treatment, and patient was discharged on the $3^{\text {rd }}$ day with S. Na+ 135 meq/l.

\section{DISCUSSION}

Rifaximin is a newer antibiotic which provides symptomatic improvement in IBS [4] such as bloating, flatulence, stool consistency, and abdominal pain. It acts by reducing the quantity of gas-producing bacteria and altering the predominant species of bacteria present, reducing mucosal inflammation, and visceral hypersensitivity [4]. There are many nonlife-threatening side effects of this drug, one of the rare side effects is hyponatremia, other drugs Which commonly causes hyponatremia are diuretics, antipsychotics, antidepressants (phenothiazine), tricyclic antidepressant, antiepileptics (oxcarbazepine, lamotrigine) cyclophosphamide, desmopressin, octreotide, vincristine, mannitol, etc.

In our patient, hyponatremia was considered as a cause of her drowsiness and after ruling out all other common causes of hyponatremia in our patient, rifaximin seems to be the incriminating cause. We are reporting this case because of the rarity of the same and probably this is the first published case of rifaximin induced hyponatremia.

\section{REFERENCES}

1. DuPont H. Therapy for and prevention of traveler's diarrhea. Clin Infect Dis 2007;45(Suppl 1):S78-84.

2. Jolley J. High-dose rifaximin treatment alleviates global symptoms of irritable bowel syndrome. Clin Exp Gastroenterol 2011;4:43-8.

3. Bass NM, Mullen KD, Sanyal A, Poordad F, Neff G, Leevy CB, et al. Rifaximin treatment in hepatic encephalopathy. N Engl J Med 2010;362:1071-81.

4. Pimentel M, Park S, Mirocha J, Kane SV, Kong Y. The effect of a nonabsorbed oral antibiotic (rifaximin) on the symptoms of the irritable bowel syndrome: A randomized trial. Ann Intern Med 2006;145(8):557-63. 